\title{
Enhancing Antidepressant Effect of Poloxamer/Chitosan Thermosensitive Gel Containing Curcumin-Cyclodextrin Inclusion Complex
}

\author{
Ye Zhang (iD) \\ Department of Pharmaceutical Sciences, Zibo Vocational Institute, Zibo 255314, China \\ Correspondence should be addressed to Ye Zhang; yezhangye2006@126.com
}

Received 26 December 2017; Revised 29 January 2018; Accepted 31 January 2018; Published 27 February 2018

Academic Editor: Angel Concheiro

Copyright (c) 2018 Ye Zhang. This is an open access article distributed under the Creative Commons Attribution License, which permits unrestricted use, distribution, and reproduction in any medium, provided the original work is properly cited.

Poor solubility and bioavailability are limiting factors for the clinical application of curcumin. This study seeks to develop poloxamer/chitosan thermosensitive gel containing curcumin-cyclodextrin inclusion complex with enhanced brain bioavailability and antidepressant effect. The optimized gel had shorter gelation time and produced sustained release in vitro characterized with non-Fickian diffusion. Pharmacokinetics of gel were evaluated using male Sprague-Dawley rats receiving $240 \mu \mathrm{g} / \mathrm{kg}$ of curcumin and curcumin-cyclodextrin inclusion complex through intranasal administration, compared against a control group receiving intravenous curcumin $(240 \mu \mathrm{g} / \mathrm{kg})$. The intranasal administration of gel provided sustained release by maintaining plasma concentrations of curcumin above $21.27 \pm 3.26 \mathrm{ng} / \mathrm{mL}$ for up to $8 \mathrm{~h}$. Compared to intranasal administration of the inclusion complex, $\mathrm{AUC}_{0-8 \mathrm{~h}}$ of curcumin from thermoreversible gel in plasma and hippocampus was increased 1.62- and 1.28-fold, respectively. The gel exhibited superior antidepressant activity in mice. The findings reported here suggested that the clinical application of curcumin can be better exploited through an intranasal administration of the thermosensitive gel.

\section{Introduction}

Intranasal drug administration has been considered to treat neuropsychiatric disorder due to the advantages brought by the highly vascularized nasal epithelium, which gives extraordinary permeability of drugs, allows high molecular mass cutoff of approximately $1000 \mathrm{Da}$, and therefore results in rapid drug absorption with plasma drug profiles almost identical to those from intravenous injections [1]. Drugs can be transported to central nervous system (CNS) along the olfactory and trigeminal neural pathways and the blood circulation [2]. The former two pathways ensure drugs reach the targeted sites of CNS to avoid the hepatic first pass effect, systemic dilution effect, and blood-brain barrier (BBB). Previous studies have demonstrated that intranasal administration offers a simple, noninvasive, convenient, and cost-effective alternative route for rapid drug delivery to the brain/CNS $[3,4]$. However, major disadvantages, such as the low bioavailability of conventional formulations, fast mucociliary clearance at human nasal cavity, and irritation caused by nasal administration, hinder the application of nasal drug discovery [5]. Therefore, in recent years, various reagents were investigated to prolong the contact time of drug molecules with the nasal mucosa, including lipid emulsions, surfactants, absorption enhancers, nanoparticle, and thermoreversible gel. Among them, thermoreversible gel is preferable in terms of patient comfort and flexibility, and it offers better accuracy in drug dosing, longer residence time, and well-controlled drug releasing.

Curcumin, known as diferuloylmethane, is a polyphenol compound isolated from the rhizomes of Curcuma longa, commonly called turmeric. It has been widely used as a spice, to color cheese and butter. In medicine, curcumin was reported to have antioxidant [6-8], hypolipidemic [9], anti-inflammatory $[10,11]$, anticancer [12], and antimetastatic [13] effects. It has been extensively studied in the prevention and treatment of Alzheimer's disease (AD) due to its anti-inflammatory and antioxidant activities. Curcumin can 
chelate $\mathrm{Cu}(\Pi), \mathrm{Al}(\amalg)$, and $\mathrm{Zn}(\Pi)$, inhibit $\beta$ amyloid formulation and aggregation [14-18], and clear $\beta$ amyloid. It lowers the hippocampal $\mathrm{NgR}$ expression and promotes axonal regeneration [19]. Curcumin also exhibits multitarget antidepressant effect through increasing serotonin (5hydroxytryptamine, 5-HT) and dopamine levels, inhibiting the monoamine oxidase enzymes (both MAO-A and MAOB) $[20,21]$ and enhancing cyclase (AC) catalytic activity and cyclic adenosine monophosphate (cAMP) concentration (AC-cAMP) and cAMP response element binding protein (CREB) [22]. Additionally, curcumin has been proved safe without dose limiting toxicity, when administered at doses up to $10 \mathrm{~g} /$ day in humans [23]. However, its poor aqueous solubility, easy degradation at neutral or alkaline $\mathrm{pH}$, high photosensitivity, and rapid metabolic turnover in the liver and intestine (mainly glucuronidation and sulfotransferase 1A1/1A3-mediated sulfation) resulted in weak bioavailability [24], which eventually limit its application in neuronal dysfunction treatment. It has been reported that curcumin was undetectable in human serum even at an oral dose of $2-8 \mathrm{~g}$ [7]. Complexation with cyclodextrins has been successfully utilized to improve solubility and bioavailability of drugs $[25,26]$. Among those different cyclodextrin derivatives, hydroxypropyl- $\beta$-cyclodextrin (HP- $\beta$-CD) is considered as one of the best due to its high solubility, good complexing properties, and absence of irritant or toxic effects.

Thus, the main purpose of current work is to develop a thermosensitive gel formulation for intranasal administration of curcumin and therefore to obtain a targeted drug absorption in the therapy of neuronal dysfunction. Poloxamer, a nontoxic poly(ethylene oxide)/poly(propylene oxide)/poly(ethylene oxide) (PEO-PPO-PEO) triblock copolymers with good tolerability, has been widely used in topical, rectal, and ocular formulations [27]. Thus, Poloxamer 407 (P407) was included in the thermosensitive gel formulation as the mucoadhesive polymer. Chitosan (CS) consisting of a copolymer of $\mathrm{N}$-acetyl-D-glucosamine and $\mathrm{D}$-glucosamine, is a natural cationic polysaccharide with wound-healing function and excellent biocompatibility with lack of toxicity and therefore is selected as a permeation enhancer [5]. HP- $\beta$-CD was attempted for nasal delivery of curcumin as a solubilizer. This is the first report on the P407/chitosan system containing the curcumin-HP$\beta$-CD inclusion complex for intranasal drug delivery. The structure of the curcumin-HP- $\beta$-CD inclusion complex and the effect of HP- $\beta$-CD on drug dissolution properties were investigated. The formulation of thermosensitive gel was designed to have high permeability and high solubility to achieve enhanced bioavailability. This gel was characterized by gelation temperature, viscoelasticity, and in vitro release characteristics. The in vivo pharmacokinetic and pharmacodynamic of the gel was evaluated in rats.

\section{Materials and Methods}

2.1. Materials and Animals. Curcumin (98\% purity) was purchased from China Food and Drug Administration (Beijing, China). Emodin (98\% purity) was provided by National Institute for the Control of Pharmaceutical and
Biological Products (Beijing, China). Chitosan (molecular weight 150,000 , deacetylation degree $75 \%-85 \%)$, HP- $\beta$-CD, Poloxamer 407 (P407), and Poloxamer 188 (Pluronic-F68) were obtained from Sigma-Aldrich Co. (St Louis, MO, USA). Polyethylene glycol 8000 (PEG8000) was purchased from Sangon Biotech (Shanghai, China). All other chemicals were of analytical reagent grade and used with no further purification.

Male ICR mice with weights of $18-20 \mathrm{~g}$ and male SpragueDawley rats with weights of 200-250 g were kept under standard conditions (temperature: $22 \pm 2^{\circ} \mathrm{C}$, relative humidity: 50-60\%) for 5 days before experiment. All animals were fasted overnight with free access to water prior to the dosing study. Animal experiments were carried out in accordance with the NIH Guide for Care and Use of Laboratory Animals. The experimental protocol was approved by the Committee on Animal Research of Zibo Institute for Food and Drug Control.

2.2. Preparation of the Curcumin-HP- $\beta-C D$ Inclusion Complex. The curcumin-HP- $\beta$-CD inclusion complex was prepared by the kneading method. In short, curcumin and cyclodextrin in the proportion of $1: 2$ molar ratio were mixed in a mortar for $1 \mathrm{~h}$ with small quantity of alcohol; distilled water was added intermittently to get slurry-like consistency. It was then dried in a hot air oven at $45^{\circ} \mathrm{C}$ for $24 \mathrm{~h}$, pulverized into fine powder, and sifted with 80 -mesh sieve.

The inclusion complex was characterized by molecular mechanics simulations. It was performed with Hypercube's hyperchem package, using the Amber force field as implemented in the program. The structure of the inclusion complex was optimized by semiempirical method PM3 with conjugated gradient at $0.1 \mathrm{kcal} / \mathrm{mol}$.

\subsection{Preparation of Thermoreversible Gels Containing the} Inclusion Complex. The thermoreversible gels were prepared by the cold method [28]. Briefly, chitosan (0.3\%, w/v) was prepared in $1 \%$ acetic acid and mixed with the curcuminHP- $\beta$-CD inclusion complex $(2 \%$, w/v, containing curcumin $0.12 \%)$. This mixture was used to dissolve P407 (20\%-21\%, $\mathrm{w} / \mathrm{v})$ and P188 to $(2 \%-3 \%, \mathrm{w} / \mathrm{v})$ make solution (Table 1$)$, which was cooled down to $4^{\circ} \mathrm{C}$ and stored overnight to ensure complete dissolution.

2.4. Measurement of Gelation Temperature. Gelation of the prepared gel was evaluated using visual inspection [5]. The gel solution $(1 \mathrm{~mL})$ was transferred to test tubes in a water bath at $10^{\circ} \mathrm{C}$ and sealed with parafilm. The bath was heated slowly to $25^{\circ} \mathrm{C}$ and left to equilibrate for $15 \mathrm{~min}$. The temperature was then increased with increment of $1^{\circ} \mathrm{C}$ until the meniscus of the gel would no longer move on tilting through $90^{\circ} \mathrm{C}$. Each sample was assayed in triplicate.

2.5. In Vitro Release Study. In vitro release study was performed using dialysis method [membrane molecular weight cutoff (MWCO): 1.2-1.4 kDa, Sigma-Aldrich Co.]. Thermoreversible gels $(2.0 \mathrm{~mL})$ were put into the dialysis membrane. Then, it was placed in a glass beaker containing $100 \mathrm{~mL}$ of 
phosphate-buffered saline $(\mathrm{pH}$ 6.4), which was preconditioned and maintained at $37^{\circ} \mathrm{C}$ in a water bath. The diffusion media were then stirred with a magnetic bar $(50 \mathrm{rpm})$. At fixed times, samples $(1 \mathrm{~mL})$ were withdrawn and immediately supplemented with the same volume of fresh media. The content of curcumin in the samples was quantified by reversed phase HPLC using an agilent SB-C18 ODS column $(250 \times$ $4.6 \mathrm{~mm}, 5 \mu \mathrm{m}$ ) with detecting wavelength at $400 \mathrm{~nm}$ (Agilent 1200 , USA). The mobile phase consisted of acetonitrile and $2 \%$ acetic acid $(50: 50)$ and the flow rate was $1.0 \mathrm{~mL} / \mathrm{min}$. The injection volume for drug analysis was $20 \mu \mathrm{L}$. The inter- and intraday variance of this HPLC method was $1.8 \%$.

\subsection{In Vivo Pharmacokinetic Study}

2.6.1. Animal Study. Twelve experimental animals were divided into two groups. For intranasal administration group, six rats were anesthetized with $5 \%$ chloral hydrate $(250 \mathrm{mg} / \mathrm{kg}$, i.p.). The curcumin-HP- $\beta$-CD inclusion complex and the thermoreversible gel were administered via a $20 \mu \mathrm{L}$ micropipette at a dose of $240 \mu \mathrm{g} / \mathrm{kg}$. For i.v. administration group, the curcumin solution $(50 \mu \mathrm{g} / \mathrm{mL})$ was injected through the caudal vein.

Blood samples $(0.5 \mathrm{~mL})$ were taken from the tail vein and centrifuged at $3500 \mathrm{rpm}$ for $10 \mathrm{~min}$ (3K15 Sigma low temperature centrifuge) to separate plasma. The collected plasma samples were stored at $-20^{\circ} \mathrm{C}$ before analysis. After sampling, the same volume of saline solution was injected to replace the removed plasma, rats were sacrificed after blood withdrawal, and the hippocampus was carefully excised, rinsed with saline, and stored at $-80^{\circ} \mathrm{C}$ until HPLC analysis.

2.6.2. Analysis of Curcumin by HPLC. Curcumin and emodin (IS) stock solution was prepared in methanol at a concentration of $436 \mathrm{ng} / \mathrm{mL}$ and $640 \mathrm{ng} / \mathrm{mL}$, respectively. Standard working solutions of curcumin were prepared by diluting with methanol. All solutions were stored at $4^{\circ} \mathrm{C}$. The calibration standards were prepared by first spiking $50 \mu \mathrm{L}$ hippocampus homogenates (hippocampus : saline $=2: 1, \mathrm{w} / \mathrm{v}$ ) or $50 \mu \mathrm{L}$ rat blank plasma with $50 \mu \mathrm{L}$ of appropriate working solution followed by addition of $50 \mu \mathrm{L}$ of IS. Three quality controls (QC) were prepared at concentrations of 20,50, and $100 \mathrm{ng} / \mathrm{mL}$ for measuring plasma samples and 20, 40, and $80 \mathrm{ng} / \mathrm{g}$ for measuring hippocampus samples. An aliquot of $50 \mu \mathrm{L}$ plasma sample was transferred to a clean centrifuge tube and mixed with $50 \mu \mathrm{L}$ of IS and $200 \mu \mathrm{L}$ of methanol to precipitate proteins. The mixture was vortexed for $5 \mathrm{~min}$ (XW-80A Microvortex mixed Miriam) and centrifuged at $14000 \mathrm{rpm}$ for $10 \mathrm{~min}$ to obtain supernatant. The supernatant was collected and an aliquot of $10 \mu \mathrm{L}$ supernatant was taken for HPLC analysis.

2.7. In Vivo Pharmacodynamic Study: Antidepressant Activity. Antagonism of reserpine-induced ptosis, akinesia, and hypothermia test was performed to evaluate the antidepressant activity of the thermoreversible gel. Briefly, mice with a rectal temperature of $36-38^{\circ} \mathrm{C}$ were used and randomly divided into six groups: control, reserpine $(2.0 \mathrm{mg} / \mathrm{kg}$ i.p. $)$, fluoxetine hydrochloride (15 mg/kg i.g.), curcumin (15 mg/kg i.g.), and thermoreversible gel $(0.18 \mathrm{mg} / \mathrm{kg}, 0.36 \mathrm{mg} / \mathrm{kg}$, and $0.72 \mathrm{mg} / \mathrm{kg}$ of curcumin via intranasal administration). Experimental mice, except for the vehicle-treated control group, received reserpine $(2.0 \mathrm{mg} / \mathrm{kg}$ i.p.) $1 \mathrm{~h}$ after drug treatments before they were placed at the center of a disk (20 $\mathrm{cm}$ of diameter). The akinesia and the degree of palpebral ptosis were measured $1 \mathrm{~h}$ after reserpine administration, and the rectal temperature were checked $2 \mathrm{~h}$ after reserpine administration. Mice were not considered akinetic when (1) walking along the edge of the disk and looking over the side; (2) moving $180^{\circ}$ in place; (3) displaying head movement of $90^{\circ}$ in one direction immediately followed by a $45^{\circ}$ movement in the opposite direction [29]. The degree of palpebral ptosis was rated according to the following scale: 0 , open; 1 , onequarter closed eyes; 2 , half-closed; 3 , three-quarters closed; and 4, completely closed eyes [30].

2.8. Data Analysis and Statistics. The results of in vitro study were expressed as the mean \pm standard deviation (SD) of three replicates while the results of the in vivo study were presented as the mean \pm standard error (SEM). Pharmacokinetic parameters were estimated using the modelindependent method. Area under the concentration-time curve (AUC) was calculated based on moment methods. Peak concentration $\left(C_{\max }\right)$ and peak time $\left(T_{\max }\right)$ were observed values. All in vivo data were compared using one-way analysis of variance (ANOVA) and values of $P<0.05$ were considered significant.

\section{Results and Discussion}

3.1. Characterization of the Curcumin-HP- $\beta-C D$ Inclusion Complex. The structure of curcumin was obtained from pubchem (CID969516). Considering the elongated, symmetrical shape of curcumin, optimization $1: 1$ host:guest complexation with binding energy of $-26267.8458 \mathrm{kcal} / \mathrm{mol}$ was illustrated in Figure 1(a). Considering the truncatedcone structure of cyclodextrin, there are three structures of 2:1 host:guest complexation (Figures 1(b), 1(c), and $1(\mathrm{~d})$ ) with the binding energy of $-47088.8920 \mathrm{kcal} / \mathrm{mol}$, $-47082.4039 \mathrm{kcal} / \mathrm{mol}$, and $-47098.8084 \mathrm{kcal} / \mathrm{mol}$, respectively. The smaller the value of the binding energy is, the better the stability of the structure is. Thus, minimum energy structures (Figure 1(d)) in which each curcumin guest is complexed by a CD host at each end of the molecule would seem the most likely inclusion scenario. This result is agreement with the previous studies which indicated that a true curcumin-HP- $\beta$-CD inclusion complex was formed at $1: 2$ in the solid state $[31,32]$, and the equilibrium constant for encapsulation by the second cyclodextrin host is significantly smaller than that for the first in each case, probably a result of steric bulk of the first cyclodextrin, with deep inclusion of the curcumin molecule, hindering encapsulation by the second cyclodextrin host [31].

3.2. Gelation Temperature of Thermoreversible Gel. Thermoreversible gel using curcumin-HP- $\beta$-CD inclusion complex has been developed for intranasal delivery of curcumin, 


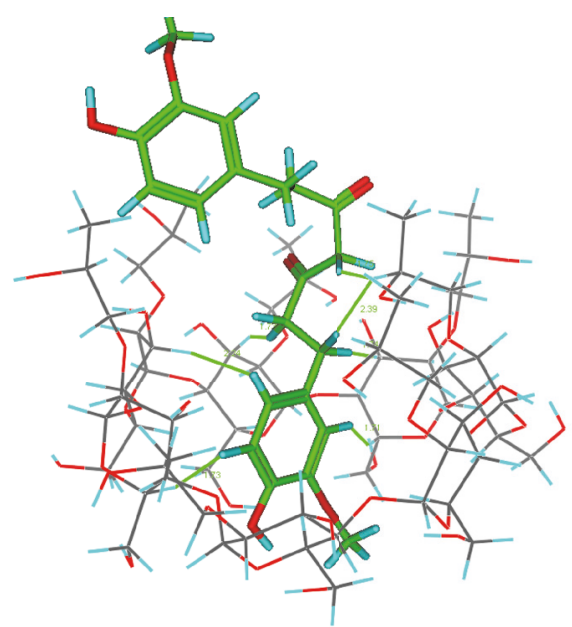

(a)

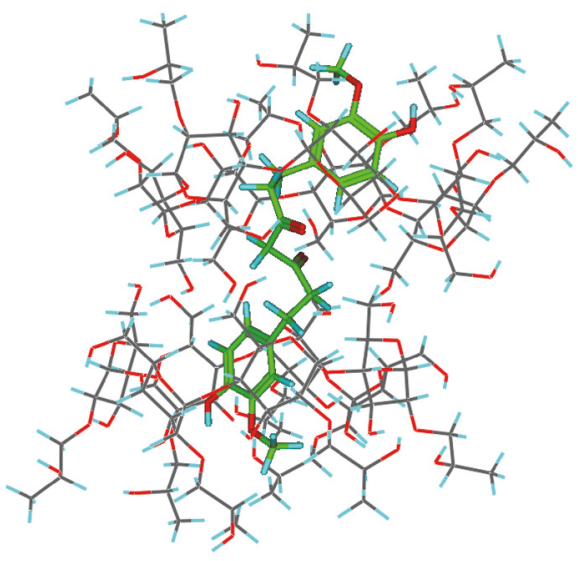

(c)

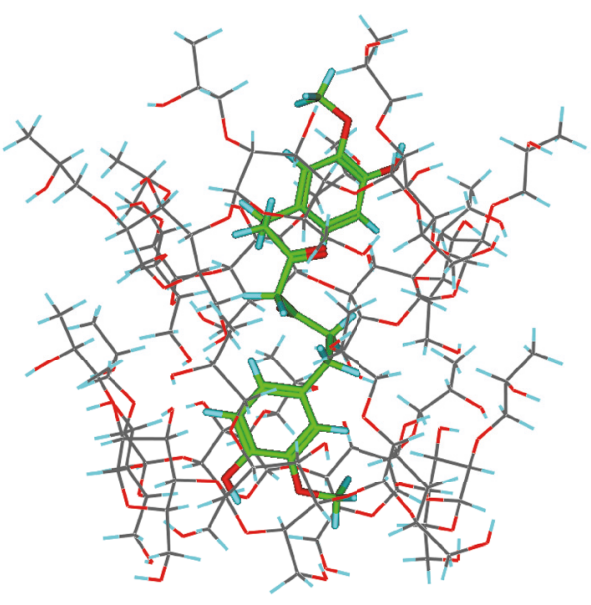

(b)

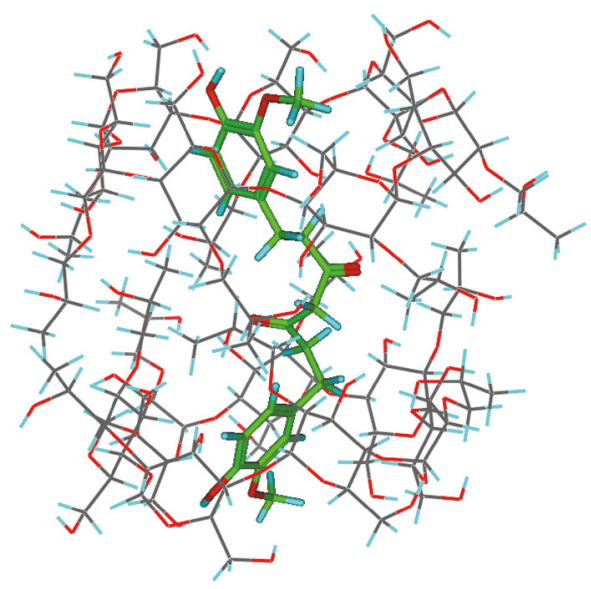

(d)

FIGURE 1: The structures of the $1: 1$ curcumin : HP- $\beta$-CD (a) and three types of $1: 2$ curcumin : HP- $\beta$-CD ((b), (c), and (d)) inclusion complex.

a drug for dysfunction CNS treatment. This approach has overcome the poor aqueous solubility of curcumin and greatly improved drug dissolution and release rate. Taking the administered dosage and solubility of the inclusion complex into consideration, the inclusion complex in rats was kept at $2 \%(\mathrm{w} / \mathrm{v})$ in all the tested formulations (Table 1$)$. Thermoreversible gel was prepared utilizing chitosan as mucoadhesive polymer and nasal absorption enhancers $[33,34]$ and P407 as thermoreversible polymer. P407, a poly(ethylene oxide)/poly(propylene oxide)/poly(ethylene oxide) $\left(\mathrm{PEO}_{99^{-}}\right.$ $\mathrm{PPO}_{67}-\mathrm{PEO}_{99}$ ) triblock copolymers, shows an incipient gelation temperature below $25^{\circ} \mathrm{C}$ and a long gelation time due to the low ratio of PEO to PPO (2.93, w/w, weight/weight). F68 exhibits a higher ratio of PEO to PPO $(3.47, \mathrm{w} / \mathrm{w})$. Thus, the addition of $\mathrm{F} 68$ in the formulation results in more hydrophilic $\mathrm{PEO}$ in the micelle, which eventually increases the incipient gelation temperature and reduces the gelation time [35]. As the temperature of the nasal cavity was around $33-34^{\circ} \mathrm{C}$, P407-based liquid formulations of the thermoreversible gel is desired to be transformed into gel when temperature is below $33^{\circ} \mathrm{C}$. The gelation temperatures of $\mathrm{F} 1$ and $\mathrm{F} 4$ were 32.3 $\pm 0.9^{\circ} \mathrm{C}$ and $30.5 \pm 0.8^{\circ} \mathrm{C}$, respectively, and the gelation times were $0.3 \pm 0.1$ and $0.7 \pm 0.3 \mathrm{~min}$, respectively. When compared to F4, F1 was closer to the physiological temperature of the nasal cavity and had a shorter gelation time. Thus, formulation F1 was chosen for the following in vitro and in vivo studies.

3.3. In Vitro Release Study. As illustrated in Figure 2, the release profiles of $\mathrm{F} 1$ and curcumin solution were extremely different. A burst release for solution was observed at beginning, and the drug was almost completely released at $4 \mathrm{~h}$ $(98.5 \% \pm 2.8)$. There was a pronounced time prolongation of the drug release from F1, where approximately $38.2 \% \pm 1.9$ of drug was released within the first $45 \mathrm{~min}$, followed by a sustained release to a total of $87.5 \% \pm 4.8$ of drug over $6 \mathrm{~h}$.

Drug release from poloxamer devices occurred either by drug diffusion through the extramicellar water channels of the gel matrix [36], by matrix erosion [37], or by a combination of both mechanisms. It can be affected by 
TABLE 1: The gelation temperature of different thermoreversible Gel formulations.

\begin{tabular}{|c|c|c|c|c|c|c|}
\hline \multirow{2}{*}{ Formulation } & \multicolumn{4}{|c|}{ Concentration $(\%, w / v)$} & \multirow{2}{*}{ Gelation temperature $\pm \mathrm{SD}\left({ }^{\circ} \mathrm{C}\right)$} & \multirow{2}{*}{ Gelation time $\pm \mathrm{SD}(\mathrm{min})$} \\
\hline & Inclusion complex & Chitosan & P407 & F68 & & \\
\hline $\mathrm{F} 1$ & 2 & 0.3 & 20 & 2 & $32.3 \pm 0.87$ & $0.3 \pm 0.1$ \\
\hline $\mathrm{F} 2$ & 2 & 0.3 & 20 & 3 & $34.3 \pm 0.34$ & - \\
\hline F3 & 2 & 0.3 & 21 & 2 & $28.1 \pm 0.52$ & $1.1 \pm 0.2$ \\
\hline $\mathrm{F} 4$ & 2 & 0.3 & 21 & 3 & $30.5 \pm 0.83$ & $0.7 \pm 0.3$ \\
\hline
\end{tabular}

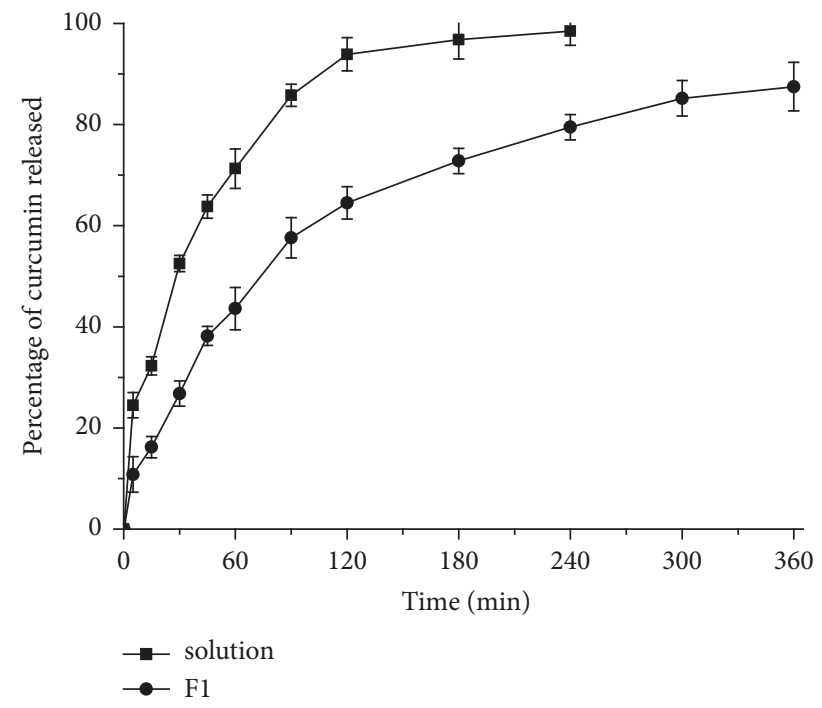

FIGURE 2: In vitro release profile of $\mathrm{F} 1$ and curcumin solution using dialysis is shown. MWCO of the dialysis membrane is $1.2-1.4 \mathrm{Da}$. Each point represents the mean $\pm \mathrm{SD}(n=3)$.

drug physicochemical properties and matrix-drug interaction [38]. The in vitro release data was analyzed by the following equation:

$$
\log \frac{M t}{M}=\log k+n \log t
$$

where $M t / M$ is the released fraction of drug, $k$ is the release constant, and $n$ is the release exponent to determine release mechanism. $n \leq 0.45$ indicates that the drug is released from the polymer by Fickian diffusion mechanism. $0.45<n<$ 0.89 indicates non-Fickian release. $n \geq 0.89$ indicates matrix erosion. In this investigation, $n$ value of thermoreversible gel was 0.52 , demonstrating that curcumin release was by nonFickian release and mainly controlled by drug diffusion and matrix erosion. The results did not agree with a previous report that stated drug diffusion controlled curcumin release from thermoreversible gel. The disagreement could be due to the difference in gel formulation recipe [35]; the gel formulation of current study contains chitosan while the previous formulation did not include chitosan.

3.4. In Vivo Pharmacokinetic Study. The HPLC method for curcumin determination and quantitation in rat plasma and hippocampus has been developed and validated. Representative chromatograms are shown in Figure 3, including a blank plasma and hippocampus sample (Figures 3(a) and $3(d))$, plasma and hippocampus containing curcumin and emodin standard (Figures 3(b) and 3(e)), and a plasma and hippocampus sample obtained $4 \mathrm{~h}$ and $2 \mathrm{~h}$, respectively, after intranasal administration of curcumin-loaded thermoreversible gel (Figure 3(c)). The resulting chromatograms show the assay specificity, as there were no endogenous plasma components eluted at the retention time of curcumin or IS.

The calibration curves were linear from 10 to $150 \mathrm{ng} / \mathrm{mL}$ $\left(r^{2}=0.9971\right)$ for plasma and $10-80 \mathrm{ng} / \mathrm{g}\left(r^{2}=0.9982\right)$ for hippocampus. The detection method was sensitive, and the LLOQ was low $(10 \mathrm{ng} / \mathrm{mL}$ for plasma and $10 \mathrm{ng} / \mathrm{g}$ for hippocampus). The mean extraction recovery ratios of three QC samples were between $92.25 \%$ and $99.67 \%$ with RSD value below $6.23 \%$ for plasma and between $93.67 \%$ and $99.89 \%$ with RSD value below $7.56 \%$ for hippocampus. The intraday and interday precision of QC samples were below $6.54 \%$ and $5.89 \%$ for plasma and hippocampus, respectively. The accuracy ranged from $94.52 \%$ to $109.96 \%$ for plasma and from $95.43 \%$ to $107.98 \%$ for hippocampus. The plasma and hippocampus samples were stable at room temperature for at least $6 \mathrm{~h}$, over three freeze/thaw cycles. They could also be kept at $-20^{\circ} \mathrm{C}$ for at least 250 days, with no significant loss of curcumin $(\leq 1.93 \%)$.

Figure 4 shows the concentration profile of curcumin in rat plasma and hippocampus over $8 \mathrm{~h}$ after $240 \mu \mathrm{g} / \mathrm{kg}$ intranasal administration of curcumin-loaded thermoreversible gel, the inclusion complex, and intravenous administration of controlled curcumin solution. After intravenous administration, curcumin displayed a multiexponential disposition with a rapid decline of the initial plasma concentration from $113.33 \pm 3.67 \mathrm{ng} / \mathrm{mL}$ to less than $41.59 \pm 2.13 \mathrm{ng} / \mathrm{mL}$ within $1 \mathrm{~h}$. Following intranasal administration of the inclusion complex, a maximum plasma concentration $\left(C_{\max }\right)$ of approximately $29.17 \pm 3.23 \mathrm{ng} / \mathrm{mL}$ was reached in $1 \mathrm{~h}$. An increased drug absorption and sustained release of curcumin over $8 \mathrm{~h}$ was observed when it was through intranasal administration of curcumin-loaded thermoreversible gel. $C_{\max }$ of approximately $31.52 \pm 1.46 \mathrm{ng} / \mathrm{mL}$ was reached in $4 \mathrm{~h}$.

Upon intravenous administration of curcumin solution, $\mathrm{AUC}_{0-8 \mathrm{~h}}$ values of curcumin in the plasma and hippocampus were $351.61 \pm 1.81 \mathrm{ng} \cdot \mathrm{h} / \mathrm{mL}$ and $217.40 \pm 10.05 \mathrm{ng} \cdot \mathrm{h} / \mathrm{g}$, respectively. By comparison, intranasal administration of the inclusion complex and thermoreversible gel gave the $\mathrm{AUC}_{0-8 \mathrm{~h}}$ values of $141.77 \pm 8.23 \mathrm{ng} \cdot \mathrm{h} / \mathrm{mL}$ and $230.56 \pm 8.95 \mathrm{ng} \cdot \mathrm{h} / \mathrm{mL}$ in plasma, respectively, and $220.17 \pm 18.75 \mathrm{ng} \cdot \mathrm{h} / \mathrm{g}$ and $282.35 \pm$ $12.20 \mathrm{ng} \cdot \mathrm{h} / \mathrm{g}$ of curcumin in hippocampus, respectively. In 


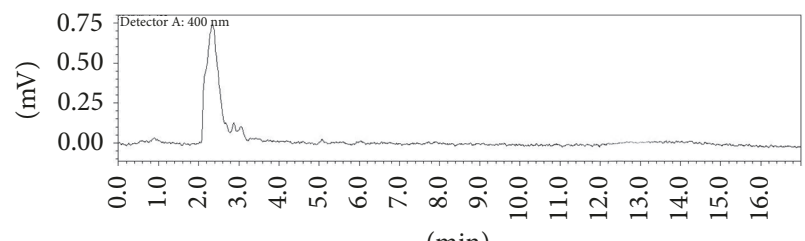

(min)

(a)

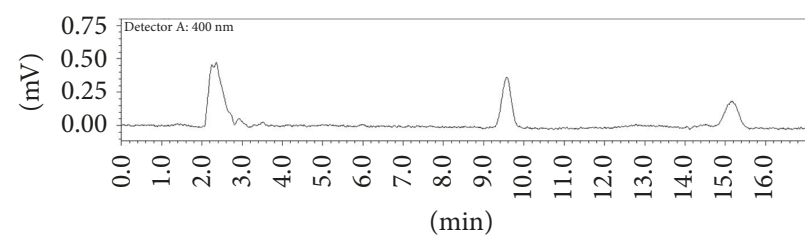

(c)

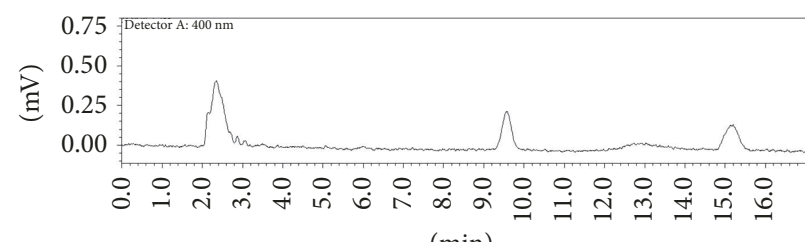

(e)

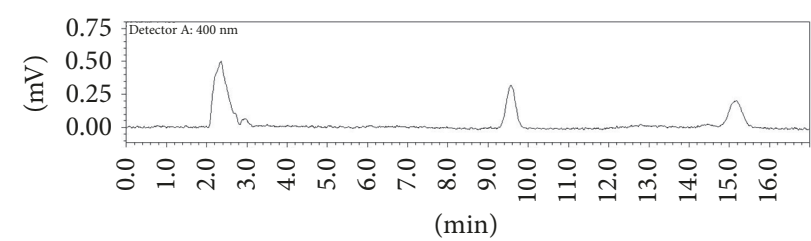

(b)

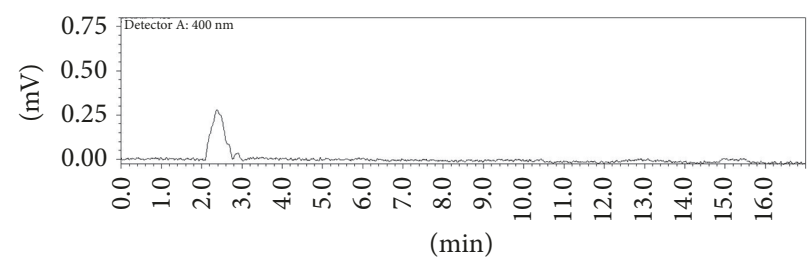

(d)

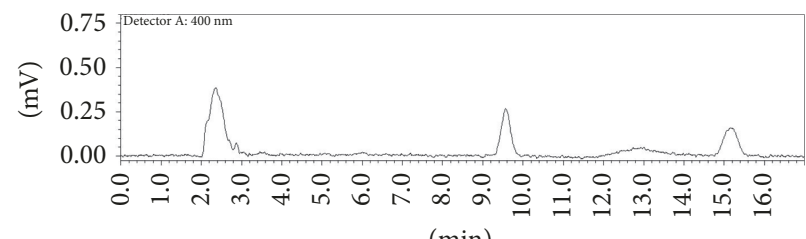

(f)

FIGURE 3: Representative chromatograms of (a) a blank plasma sample, (b) a curcumin standard in plasma (46.5 ng/mL of curcumin), (c) a curcumin sample in plasma, (d) a blank hippocampus sample, (e) a curcumin standard in hippocampus ( $39.2 \mathrm{ng} / \mathrm{mL}$ of curcumin), and (f) a curcumin sample in hippocampus. The left peak (retention time of 9.5) of the figure is representative of curcumin and the right (retention time of 15.2) is indicative of the peak of the internal standard.
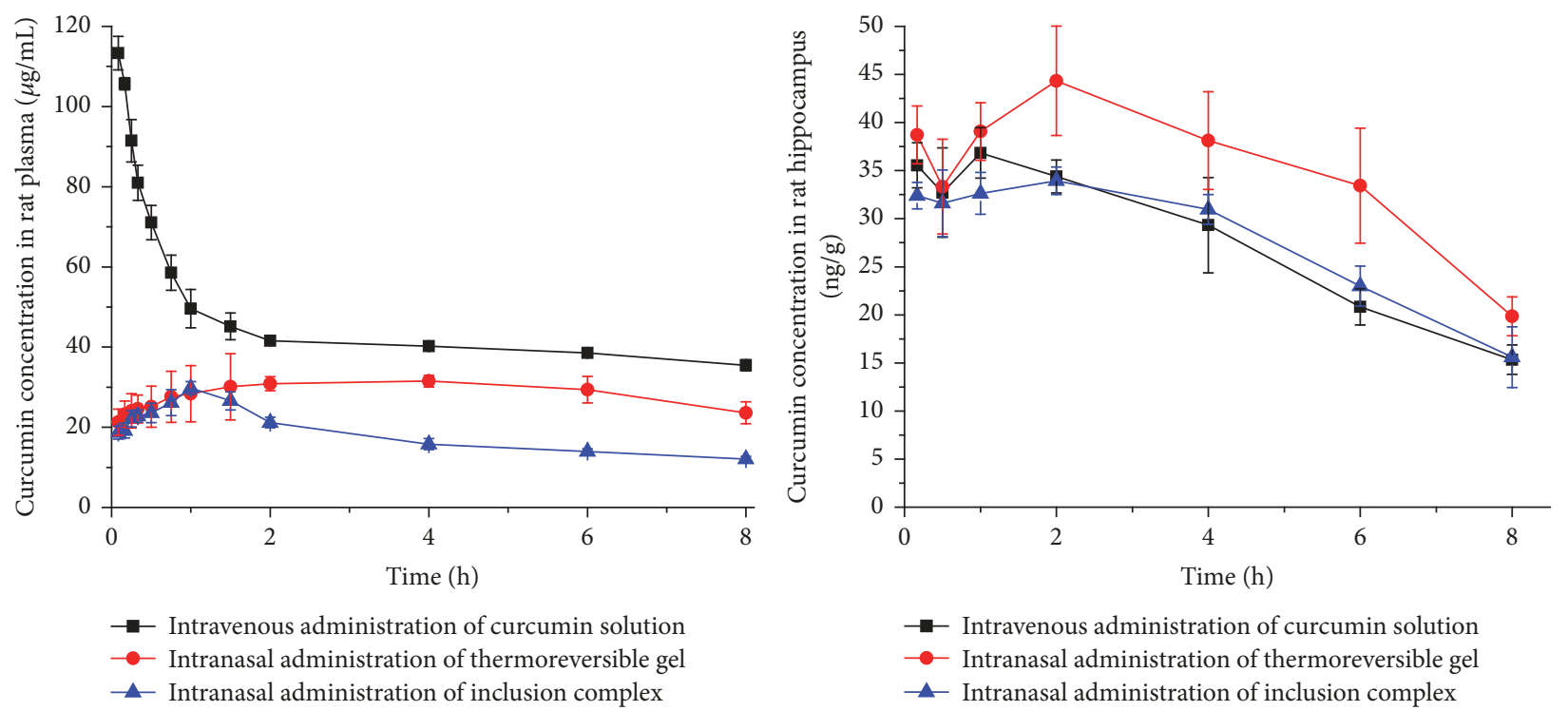

FIGURE 4: Curcumin concentration profile in plasma and hippocampus of male Sprague-Dawley rats after $240 \mu \mathrm{g} / \mathrm{kg}$ intranasal administration of the inclusion complex and the thermoreversible gel and $240 \mu \mathrm{g} / \mathrm{kg}$ intravenous administration of curcumin solution over $8 \mathrm{~h}$.

other words, compared to intranasal administration of the inclusion complex, $\mathrm{AUC}_{0-8 \mathrm{~h}}$ of curcumin from thermoreversible gel in plasma was increased 1.62-fold. Interestingly, the absolute bioavailability in hippocampus was significantly enhanced 1.30-fold. The curcumin concentration in the brain when using intranasal administration was higher than that of using intravenous administration over the experimental time $(8 \mathrm{~h})$, especially in the last $6 \mathrm{~h}$.

Curcumin released from thermoreversible gel may take two metabolic pathways to enter brain, which can explain the higher $\mathrm{AUC}_{2-8 \mathrm{~h}}$ of curcumin in hippocampus observed in nasal administration group. The first pathway curcumin 
TABLE 2: Effect of thermoreversible gel on reserpine-induced ptosis, akinesia, and hypothermia.

\begin{tabular}{lcccc}
\hline Treatment & Dose $(\mathrm{mg} / \mathrm{kg})$ & Ptosis mean score & Akinesia (mice number) & Rectal temperature $\left({ }^{\circ} \mathrm{C}\right)$ \\
\hline Control & - & 0 & 0 & $37.3 \pm 0.54$ \\
Reserpine & 2.0 & $2.00 \pm 0.67^{\# \#}$ & 9 & $34.75 \pm 0.78^{\# \#}$ \\
Fluoxetine hydrochloride & 15 & $1.10 \pm 0.32^{* *}$ & 7 & $35.91 \pm 0.53^{* *}$ \\
Curcumin & 15 & $1.82 \pm 0.97$ & 8 & $35.11 \pm 0.98$ \\
& 0.18 & $1.20 \pm 0.63^{*}$ & 8 & $35.69 \pm 1.02^{*}$ \\
Thermoreversible gel & 0.36 & $1.10 \pm 0.74^{*}$ & 7 & $36.25 \pm 1.09^{* *}$ \\
& 0.72 & $1.00 \pm 0.47^{* *}$ & 6 & $36.7 \pm 0.82^{* *}$ \\
\hline
\end{tabular}

${ }^{\# \#} P<0.01$ compared with control group; ${ }^{*} P<0.05,{ }^{* *} P<0.01$ compared with reserpine.

taken is blood diffusion, by which curcumin can further cross the $\mathrm{BBB}$ and reach brain. The second pathway is through the olfactory and trigeminal neural pathways to enter the brain, which avoids metabolism in the liver and intestine where the metabolic product of curcumin (tetrahydrocurcumin) was produced. In general, due to the different PK behavior of curcumin when it is complexed in thermoreversible gel, nasal delivery by thermoreversible gel greatly enhanced the bioavailability of curcumin in vivo.

3.5. In Vivo Pharmacodynamic Study: Antidepressant Activity. In the reserpine test (Table 2), reserpine significantly increased the ptosis mean score and considerably decreased the rectal temperature and locomotor activity. Fluoxetine hydrochloride (the antidepressant agent used as a reference drug) greatly antagonized ptosis, akinesia, and hypothermia. Curcumin $(15 \mathrm{mg} / \mathrm{kg})$ slightly antagonized ptosis, akinesia, and hypothermia. Thermoreversible gel at the three dosages significantly antagonized all the effects induced by reserpine. The results indicate that thermoreversible gel containing the curcumin-HP- $\beta$-CD inclusion complex possesses superior antidepressant effect.

\section{Conclusions}

On the basis of the fact that chitosan and drug-HP- $\beta$-CD can enhance the intranasal permeation of drug moiety, an optimized thermoreversible gel for intranasal delivery of curcumin was formulated. The thermoreversible gel displayed sustained curcumin release in vitro and an enhanced brain uptake of curcumin as compared to intravenous administration in vivo. It also showed superior antidepressant activity. Thus, poloxamer/chitosan thermoreversible nasal gel containing drug-cyclodextrin inclusion complex can shed light on the design of new controlled delivery for the curcumin administration to treat depression.

\section{Conflicts of Interest}

The author declares that there are no conflicts of interest regarding the publication of this paper.

\section{Acknowledgments}

This work was supported by Science and Technology Development Plan Project of Zibo City under Grants 2016kj010052 and 2017kj010043.

\section{References}

[1] M. I. Ugwoke, N. Verbeke, and R. Kinget, "The biopharmaceutical aspects of nasal mucoadhesive drug delivery," Journal of Pharmacy and Pharmacology, vol. 53, no. 1, pp. 3-21, 2001.

[2] L. Illum, "Nasal drug delivery-possibilities, problems and solutions," Journal of Controlled Release, vol. 87, no. 1-3, pp. 187198, 2003.

[3] T. K. Vyas, A. Shahiwala, S. Marathe, and A. Misra, "Intranasal drug delivery for brain targeting," Current Drug Delivery, vol. 2, no. 2, pp. 165-175, 2005.

[4] V. Jogani, K. Jinturkar, T. K. Vyas, and A. Misra, "Recent patents review on intranasal administration for CNS drug delivery," Recent Patents on Drug Delivery and Formulation, vol. 2, no. 1, pp. $25-40,2008$.

[5] H.-J. Cho, P. Balakrishnan, E.-K. Park et al., "Poloxamer/cyclodextrin/chitosan-based thermoreversible gel for intranasal delivery of fexofenadine hydrochloride," Journal of Pharmaceutical Sciences, vol. 100, no. 2, pp. 681-691, 2011.

[6] M.-L. Kuo, T.-S. Huang, and J.-K. Lin, "Curcumin, an antioxidant and anti-tumor promoter, induces apoptosis in human leukemia cells," Biochimica et Biophysica Acta (BBA) - Molecular Basis of Disease, vol. 1317, no. 2, pp. 95-100, 1996.

[7] R. A. Sharma, H. R. McLelland, K. A. Hill et al., "Pharmacodynamic and pharmacokinetic study of oral Curcuma extract in patients with colorectal cancer," Clinical Cancer Research, vol. 7, pp. 1894-1900, 2001.

[8] A. Dairam, R. Fogel, S. Daya, and J. L. Limson, "Antioxidant and iron-binding properties of curcumin, capsaicin, and Sallylcysteine reduce oxidative stress in rat brain homogenate," Journal of Agricultural and Food Chemistry, vol. 56, no. 9, pp. 3350-3356, 2008.

[9] P. S. Babu and K. Srinivasan, "Hypolipidemic action of curcumin, the active principle of turmeric (Curcuma longa) in streptozotocin induced diabetic rats," Molecular and Cellular Biochemistry, vol. 166, no. 1-2, pp. 169-175, 1997.

[10] H. P. T. Ammon, N. Safayhi, T. Mack, and J. Sabieraj, "Mechanism of antiinflammatory actions of curcumine and boswellic acids," Journal of Ethnopharmacology, vol. 38, no. 2-3, pp. 113$119,1993$.

[11] A. Pulla Reddy Ch. and B. R. Lokesh, "Studies on antiinflammatory activity of spice principles and dietary n-3 polyunsaturated fatty acids on carrageenan-induced inflammation in rats," Annals of Nutrition and Metabolism, vol. 38, no. 6, pp. 349-358, 1994. 
[12] B. B. Aggarwal and K. B. Harikumar, "Potential therapeutic effects of curcumin, the anti-inflammatory agent, against neurodegenerative, cardiovascular, pulmonary, metabolic, autoimmune and neoplastic diseases," The International Journal of Biochemistry \& Cell Biology, vol. 41, no. 1, pp. 40-59, 2009.

[13] A. Chatterjee, A. Mitra, S. Ray, N. Chattopadhyay, and M. Siddiqi, "Curcumin Exhibits Antimetastatic Properties by Modulating Integrin Receptors, Collagenase Activity, and Expression of Nm23 and E-Cadherin," Journal of Environmental Pathology, Toxicology and Oncology, vol. 22, no. 1, pp. 47-56, 2003.

[14] X. Zhang, H. Zhang, L. Si, and Y. Li, "Curcumin mediates presenilin- 1 activity to reduce $\beta$-amyloid production in a model of Alzheimer's disease," Pharmacological Reports, vol. 63, no. 5, pp. 1101-1108, 2011.

[15] T. Jiang, X.-L. Zhi, Y.-H. Zhang, L.-F. Pan, and P. Zhou, "Inhibitory effect of curcumin on the $\mathrm{Al}(\mathrm{III})$-induced $\mathrm{A} \beta_{42}$ aggregation and neurotoxicity in vitro," Biochimica et Biophysica Acta (BBA) - Molecular Basis of Disease, vol. 1822, no. 8, pp. 1207-1215, 2012.

[16] A. L. Picciano and T. D. Vaden, "Complexation between $\mathrm{Cu}$ (II) and curcumin in the presence of two different segments of amyloid $\beta$," Biophysical Chemistry, vol. 184, pp. 62-67, 2013.

[17] Y. Wang, H. Yin, L. Wang et al., "Curcumin as a potential treatment for Alzheimer's disease: a study of the effects of curcumin on hippocampal expression of glial fibrillary acidic protein," American Journal of Chinese Medicine, vol. 41, no. 1, pp. 59-70, 2013.

[18] R. Banerjee, "Effect of Curcumin on the metal ion induced fibrillization of Amyloid- $\beta$ peptide," Spectrochimica Acta Part A: Molecular and Biomolecular Spectroscopy, vol. 117, pp. 798-800, 2014.

[19] H. L. Yin, Y. L. Wang, J. F. Li et al., "Effects of curcumin on hippocampal expression of $\mathrm{NgR}$ and axonal regeneration in $\mathrm{A} \beta$-induced cognitive disorder rats," Genetics and Molecular Research, vol. 13, no. 1, pp. 2039-2047, 2014.

[20] Y. Xu, B. S. Ku, H. Y. Yao et al., "Antidepressant effects of curcumin in the forced swim test and olfactory bulbectomy models of depression in rats," Pharmacology Biochemistry \& Behavior, vol. 82, no. 1, pp. 200-206, 2005.

[21] S. K. Kulkarni, M. K. Bhutani, and M. Bishnoi, "Antidepressant activity of curcumin: Involvement of serotonin and dopamine system," Psychopharmacology, vol. 201, no. 3, pp. 435-442, 2008.

[22] Y.-C. Li, F.-M. Wang, Y. Pan et al., "Antidepressant-like effects of curcumin on serotonergic receptor-coupled AC-cAMP pathway in chronic unpredictable mild stress of rats," Progress in Neuro-Psychopharmacology \& Biological Psychiatry, vol. 33, no. 3, pp. 435-449, 2009.

[23] N. Chainani-Wu, "Safety and anti-inflammatory activity of curcumin: a component of tumeric (Curcuma longa)," The Journal of Alternative and Complementary Medicine, vol. 9, no. 1, pp. 161-168, 2003.

[24] S. Zhou, L. Y. Lim, and B. Chowbay, "Herbal modulation of Pglycoprotein,” Drug Metabolism Reviews, vol. 36, no. 1, pp. 57104, 2004.

[25] M. E. Davis and M. Brewster, "Cyclodextrin-based pharmaceutics: past, present and future," Nature Reviews Drug Discovery, vol. 3, pp. 1023-1035, 2004.

[26] S. M. N. Simões, A. Rey-Rico, A. Concheiro, and C. AlvarezLorenzo, "Supramolecular cyclodextrin-based drug nanocarriers," Chemical Communications, vol. 51, no. 29, pp. 6275-6289, 2015.
[27] G. Dumortier, J. L. Grossiord, F. Agnely, and J. C. Chaumeil, "A review of poloxamer 407 pharmaceutical and pharmacological characteristics," Pharmaceutical Research, vol. 23, no. 12, pp. 2709-2728, 2006.

[28] I. R. Schmolka, "Artificial skin. I. Preparation and properties of pluronic F-127 gels for treatment of burns," Journal of Biomedical Materials Research Part B: Applied Biomaterials, vol. 6, no. 6, pp. 571-582, 1972.

[29] E. N. Greenblatt, A. S. Lippa, and A. C. Osterberg, "The neuropharmacological actions of amoxapine," Archives Internationales De Pharmacodynamie Et De Therapie, vol. 233, pp. 10735, 1978.

[30] H. G. Alpermann, U. Schacht, P. Usinger, and F. J. Hock, "Pharmacological effects of Hoe 249: A new potential antidepressant," Drug Development Research, vol. 25, no. 4, pp. 267-282, 1992.

[31] K. N. Baglole, P. G. Boland, and B. D. Wagner, "Fluorescence enhancement of curcumin upon inclusion into parent and modified cyclodextrins," Journal of Photochemistry and Photobiology A: Chemistry, vol. 173, no. 3, pp. 230-237, 2005.

[32] V. R. Yadav, S. Suresh, K. Devi, and S. Yadav, "Effect of cyclodextrin complexation of curcumin on its solubility and antiangiogenic and anti-inflammatory activity in rat colitis model," AAPS PharmSciTech, vol. 10, no. 3, pp. 752-762, 2009.

[33] P. Tengamnuay, A. Sahamethapat, A. Sailasuta, and A. K. Mitra, "Chitosans as nasal absorption enhancers of peptides: Comparison between free amine chitosans and soluble salts," International Journal of Pharmaceutics, vol. 197, no. 1-2, pp. 53$67,2000$.

[34] P. Sinswat and P. Tengamnuay, "Enhancing effect of chitosan on nasal absorption of salmon calcitonin in rats: Comparison with hydroxypropyl- and dimethyl- $\beta$-cyclodextrins," International Journal of Pharmaceutics, vol. 257, no. 1-2, pp. 15-22, 2003.

[35] X. Chen, F. Zhi, X. Jia et al., "Enhanced brain targeting of curcumin by intranasal administration of a thermosensitive poloxamer hydrogel," Journal of Pharmacy and Pharmacology, vol. 65, no. 6, pp. 807-816, 2013.

[36] V. Nair and R. Panchagnula, "Poloxamer gel as vehicle for transdermal iontophoretic delivery of arginine vasopressin: Evaluation of in vivo performance in rats," Pharmacological Research, vol. 47, no. 6, pp. 555-562, 2003.

[37] T. Moore, S. Croy, S. Mallapragada, and N. Pandit, "Experimental investigation and mathematical modeling of Pluronic F127 gel dissolution: drug release in stirred systems," Journal of Controlled Release, vol. 67, no. 2-3, pp. 191-202, 2000.

[38] D. Puppi, A. M. Piras, N. Detta, D. Dinucci, and F. Chiellini, "Poly(lactic-co-glycolic acid) electrospun fibrous meshes for the controlled release of retinoic acid," Acta Biomaterialia, vol. 6, no. 4, pp. 1258-1268, 2010. 


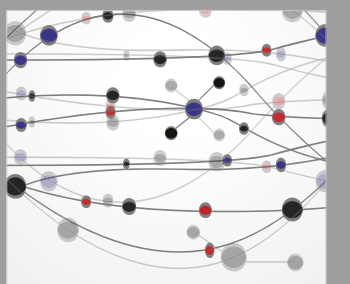

The Scientific World Journal
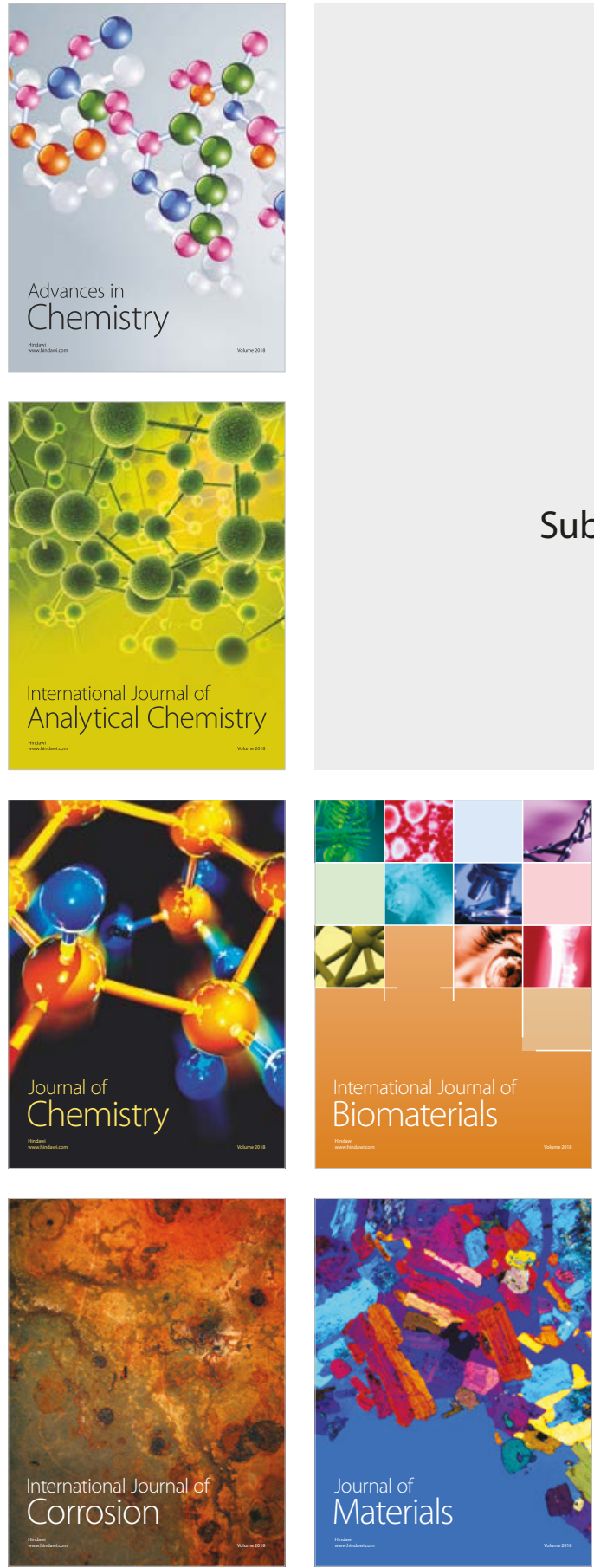

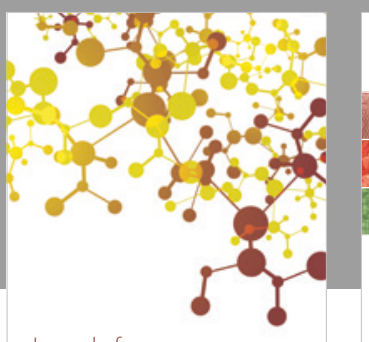

Journal of

Applied Chemistry
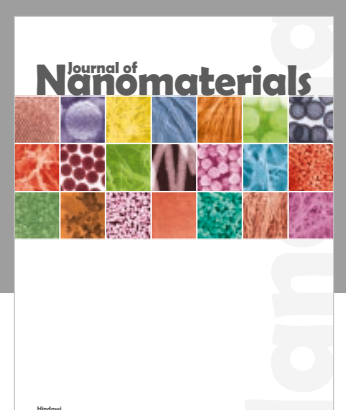

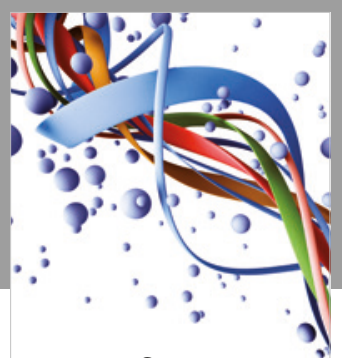

Scientifica

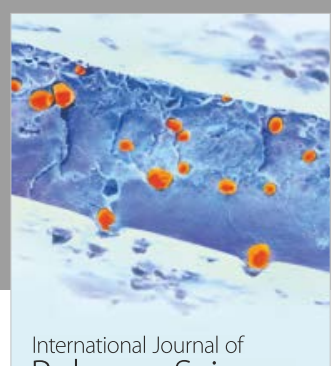

Polymer Science

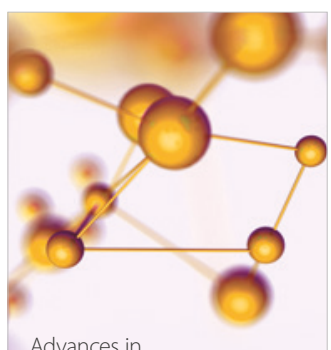

Physical Chemistry
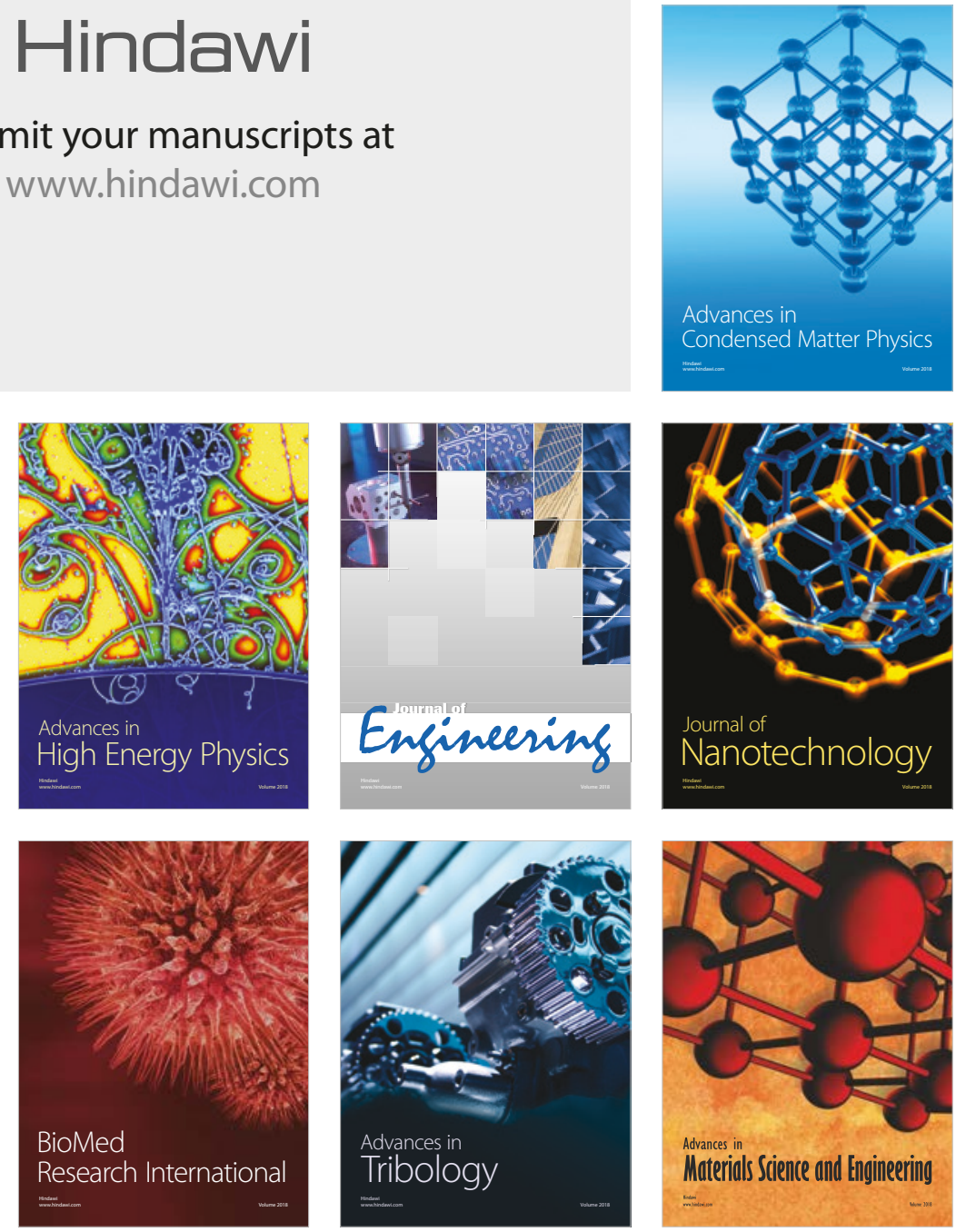